Studia nad Autorytaryzmem i Totalitaryzmem 43, nr 2

Wrocław 2021

https://doi.org/10.19195/2300-7249.43.2.13

\author{
PRZEMYSŁAW KACZMAREK \\ ORCID: 0000-0002-3436-4043 \\ Uniwersytet Wrocławski \\ przemysław.kaczmarek@uwr.edu.pl
}

\title{
Teatralność procesu sądowego: kilka uwag o profesjonalizmie*
}

\begin{abstract}
Słowa kluczowe: proces sądowy, teatr, prawnik, sędzia, profesjonalizm, moralność instytucjonalna, totalność.
\end{abstract}

\section{The theatricality of the court trial: A few remarks on professionalism}

\begin{abstract}
The aim of the paper is to answer the question: what image of a professional role does the vision of a court trial as a theatre contain? In carrying out such a task, first of all, I will present the reasons that justify comparing the theatrical practice to a court hearing. When carrying out this procedure, I will pay attention to the concept of role, the ritualization of activities, the architecture of space, and functions of the role performers' clothing. From these findings, a dramatical vision of a court trial emerges, modelled on a theatrical performance. It assumes that the performing of a role by the actor and the judge or the lawyer is largely defined by factors external to the interpreter. Such an approach to the exercise of the profession can be related to the dramatic vision of the role in Erving Goffman's theatrical metaphor. In this perspective, it is assumed that exercising a role is a performance that can lead to two images of the professional ethos. They are characterized by an attitude of identification with the role and an instrumental distance to the profession. I intend to question both of these views. By carrying out this task, I will show that presenting a court trial as a theater does not have to assume the image of a judge, a lawyer whose task is to develop the ability to adapt to the rules of the profession and faithfully reproduce them in the cases under consideration. In presenting this position, I use the findings of theatrologist Jerzy Grotowski and the anthropological research of Victor Turner, focusing on the idea of liminality.
\end{abstract}

Keywords: court trial, theatre, lawyer, judge, professionalism, institutional morality, totality.

* Artykuł powstał w ramach realizacji projektu badawczego Narodowego Centrum Nauki nr 2020/37/B/HS5/00297.

Studia nad Autorytaryzmem i Totalitaryzmem 43, nr 2, 2021

(C) for this edition by CNS 


\section{Wprowadzenie}

Tytuł niniejszego artykułu nawiązuje do diagnozy Ervinga Goffmana, według której życie codzienne przypomina spektakl teatralny ${ }^{1}$. W myśl tej diagnozy człowiek jest społecznym aktorem, który na scenie, jaką jest życie codzienne, odgrywa role. Dla wyłaniającego się z odgrywanych ról porządku społecznego ważne są scenariusze, które wyznaczają ramy dokonywanych interakcji, powodując jednocześnie, że jesteśmy w pewnym stopniu aktorami. Ustalenia te zostały zaadoptowane do badania różnych praktyk społecznych, w tym i rozprawy sądowej. Jednym z autorów, który dokonał takiego zabiegu jest Jacek Chlebny, zdaniem którego

truizmem jest twierdzenie, że sala sądowa jest w pewnym sensie teatrem, w którym aktorzy adwokaci, sędzia i inni uczestnicy rozprawy — mają z góry określone role do odegrania. [...] spór na sali sądowej poddaje się opisowi według reguł właściwych dla teatru. Treść wystąpień aktorów (uczestników rozprawy) nie jest wprawdzie znana, ale role do odegrania i zasady udziału w przedstawieniu (w rozprawie sądowej) są jasno zdefiniowane [...]"2.

Z wypowiedzi J. Chlebnego można wyprowadzić co najmniej dwa wnioski. Po pierwsze, teatralność praktyki sądowej jest faktem społecznym. Po drugie zaś, podstaw tej analogii upatruje się w odgrywaniu roli, odpowiednio przez aktora i sędziego, która jest w znacznym stopniu zdefiniowana przez czynniki zewnętrzne względem interpretatora.

W artykule, akceptując pierwszy z wymienionych wniosków, chciałbym jednocześnie podać w wątpliwość drugi. W tym celu zamierzam wykazać, że przedstawianie procesu sądowego jako teatru nie musi zakładać obrazu sędziego, prawnika, którego zadaniem staje się dostosowanie do reguł profesji i ich wierne odtwarzanie w rozpatrywanych sprawach. Tak postawione zadanie zostanie zrealizowane w trzech punktach. Najpierw przedstawię racje uzasadniające budowanie analogii między praktyką teatralną a sądową. W kolejnych dwóch krokach ukażę odmienne wizje wykonywania roli, jakie ilustruje perspektywa teatralna w ujęciu, odpowiednio, Ervinga Goffmana i Jerzego Grotowskiego.

W celu uniknięcia ewentualnych wątpliwości, chciałbym zaznaczyć, że terminem ,prawnik" posługuję się w dwóch znaczeniach: szerszym i węższym. Pierwsze z ujęć swym zakresem obejmuje osoby wykonujące różne profesje prawnicze, z kolei drugie - tylko zawód pełnomocnika procesowego. Jeśli z kontekstu

${ }^{1}$ E. Goffman, Człowiek w teatrze życia codziennego, przeł. H. Datner-Śpiewak, P. Śpiewak, Warszawa 2008, s. 27.

2 J. Chlebny, Dramaturgia sali sądowej. Próba zastosowania kategorii Ervinga Goffmana, [w:] Etyka zawodów prawniczych w praktyce. Wzajemne relacje i oczekiwania, red. G. Borkowski, Lublin 2012, s. 74. Por. B. Tecław, Rozprawa sadowa jako spektakl teatralny, [w:] Język prawny i prawniczy. I Kongres ogólnopolski, red. D. Kondratczyk-Przybylska, A. Niewiadomski, E. Walewska, Warszawa 2017, s. 252. 
rozważań nie wynika inaczej, to pojęcia prawnika używam w pierwszym znaczeniu i w tym przypadku posługuję się nim zamiennie z określeniem ,jurysta”.

\section{Proces sądowy jako teatr}

Porównanie zawodu prawnika, w szczególności sędziego, do aktora, wymaga wyjaśnienia. Jak już wspomniałem, metafora teatralna jest obecna w przedstawianiu praktyki prawniczej, zwłaszcza rozprawy sądowej ${ }^{3}$. Niemniej jednak ukazanie związku między obrazem sceny teatralnej a sali sądowej wymaga uzasadnienia. W tym celu wskażmy na kilka racji, przemawiających za dokonywaniem takiej analogii.

Po pierwsze, podobieństwa między obiema interesującymi nas praktykami można dostrzec uwzględniając aspekt historyczny. Dokumentując to, Dermot Nolan początków porównywania prawa do teatru upatruje w starożytnych Atenach ${ }^{4}$. Julie Stone Peters, podążając tym tropem, wskazuje na funkcje obu praktyk: służą rozwiązywaniu konfliktów, sprzyjają konsolidacji wspólnoty ${ }^{5}$.

Po drugie, podobieństw można upatrywać w pojęciu roli. Zdaniem Floriana Znanieckiego termin ,rola” $w$ teorii społecznej został zaczerpnięty $\mathrm{z}$ teatru ${ }^{6}$ $\mathrm{i}$ tą drogą został zaadoptowany w jurysprudencji ${ }^{7}$. Podstawą tego odniesienia są trzy właściwości pojęcia roli ${ }^{8}$. Pierwsza z nich podkreśla aspekt interakcji między ekspertami oraz wykonawcą roli a publicznością. Jest on obecny w praktyce prawniczej. Podobnie jak kolejna, druga właściwość w postaci struktury instytucjonalnej, która, przynajmniej ramowo, kształtuje wzorzec wykonywania roli, zarówno w teatrologii, jak i dyskursie prawniczym. Wskazana ramowość eksponuje pytanie o wpływ czynników indywidualno-sytuacyjnych na treść czynności zawodowych.

Po trzecie, obie profesje łączy spór o wizję wykonywania roli. Modelowo można wyróżnić dwa stanowiska. Pierwsze, zgodnie z którym zadaniem aktora

3 Poza przedmiotem analiz pozostawiam rozważania Pierre Legendre, korzystającego z metafory teatralnej. Zainteresowanego czytelnika odsyłam do tekstu J.S. Peters, Legal Performance Good and Bad, „Law, Culture and the Humanities” 4, 2008, s. 188-191.

4 Za: R. Gilbert, Editorial, „Canadian Theatre Review” 2010, nr 142, s. 3. Por. J.N. Nikova, The concept of 'theatricality' in legal performance with respect to musicians and the way they engage with the law, http://lawreview.elsa-spain.org/wp-content/uploads/2017/06/Art5.pdf; oraz M. Szerer, Kultura i prawo, Warszawa 1981, s. 224 n.

5 J.S. Peters, op. cit., s. 181.

${ }^{6}$ F. Znaniecki, Relacje społeczne i role społeczne. Niedokończona socjologia systematyczna, przeł. E. Hałas, Warszawa 2001, s. 270.

7 Zob. G. Skąpska, Dramaturgia procesu sądowego, [w:] G. Skąpska, J. Czapska, M. Kozłowska, Społeczne role prawników (sędziów, prokuratorów, adwokatów), Wrocław 1980, s. 55 n.; W. Świerczyńska-Głownia, Komunikowanie z perspektywy sali sadowej, Kraków 2019, s. 26-33.

8 F. Znaniecki, op. cit., s. 272-276. 
czy jurysty jest posiadanie umiejętności dostosowywania reguł do zmieniającej się sytuacji. Z kolei druga wizja zakłada, że zadanie to sprowadza się jedynie do wiernego odtwarzania reguł praktyki, której jest się wykonawcą. W sporze tym uwidaczniają się dwie strategie rozstrzygania relacji między tekstem a interpretatorem ${ }^{9}$.

Po czwarte, zawód aktora, jak i jurysty, koncentruje się na rytualizacji czynności ${ }^{10}$. Elementy rytualne są obecne $\mathrm{w}$ procesach sądowych oraz przedstawieniach teatralnych ${ }^{11}$. Zewnętrznym wyrazem tej rytualizacji jest strój uczestników obu praktyk $^{12}$. Jak odnotowuje Aoife Monks, zarówno na sali sądowej, jak i na deskach teatru, strój jest znakiem wkroczenia osoby w rolę. Podobnie też ściągnięcie togi można odczytywać jako wyjście $\mathrm{z}$ roli ${ }^{13}$. Funkcję szat $\mathrm{w}$ obu analizowanych praktykach można rozpatrywać nie tylko z punktu widzenia obserwatora, ale i profesjonalisty. Z jednej strony zatem ubiór pełni funkcję informacyjną dla obserwatora, podkreślając fakt dokonywania czynności przez osobę w roli. $Z$ drugiej zaś, bycie w roli odciąża w pewien sposób wykonawcę, ponieważ pozwala racjonalizować podejmowane działania argumentem z profesjonalizmu zawodowego ${ }^{14}$.

Po piąte, podstaw porównywania rozprawy sądowej do teatru można upatrywać $\mathrm{W}$ architekturze przestrzeni ${ }^{15}$. W obu praktykach mamy zaprojektowaną salę, jej przestrzeń ma określone strefy, a samo wydarzenie jest ograniczone co do miejsca i czasu. Z tego też powodu można wyróżnić scenę, kulisy. W centrum wydarzeń usytuowana jest scena, do której dostęp mają główni wykonawcy przedstawienia. W przypadku praktyki sądowej są nimi świadkowie, strony sporu i skład orzekający. Według Milnera S. Balla sędziowie występują w dwóch rolach, co wynika z tego, że procesy sądowe obejmują dwie odrębne sztuki: małą

9 N. Rogers, The Play of law: Comparing performances in law and theatre, „QUT Law Review" 8, 2008, nr 2, s. 431-432. Zob. też H.T. Lehmann, Teatr postdramatyczny, przeł. D. Sajewska, M. Sugiera, Kraków 2004, s. 66-70.

10 M.S. Ball, The Play's the Thing: An Unscientific Reflection on Courts Under the Rubric of Theater, „Stanford Law Review” 28, 1975, nr 1, s. 83 n.; P. Goodrich, Europe in America: Grammatology, Legal Studies, and the Politics of Transmission, „Columbia Law Review” 101, 2001, nr 8, s. 2080; J.S. Peters, op. cit., s. 181-183; D.J. Brion, The Criminal Trial as Theater: The Semiotic Power of the Image, [w:] Law, Culture and Visual Studies, red. A. Wagner, R.K. Sherwin, Dordrecht 2014, s. 342-347; R. Tokarczyk, Proksemika ogólna jako podstawa proksemiki sadowej i proksemiki prawniczej, „Annales Universitatis Mariae Curie-Skłodowska, Secio G” 56-57, 20092010, s. 193-194.

11 A.G. Boss, (Un)related Purposes: Theatre and Law, „Canadian Theatre Review” 2010, nr 142 , s. 31.

12 A. Monks, Dressing the law, „International Journal of Law in Context” 14, 2018, nr 4, s. 480.

13 C. Gemli, Staging the nation: Theatricality in the Law, „Elements” 2005, nr 1, s. 60.

14 M.S. Ball, op. cit., s. 109-110.

15 C. Vismann, “Rejouer les crimes” Theater vs. Video, „Cardozo Studies in Law and Literature" 13, 2001, nr 1, s. 127; M.S. Ball, op. cit., s. 83-84. 
i dużą ${ }^{16}$. Pierwsza $z$ nich odgrywana jest przez pełnomocników procesowych, reprezentujących strony sporu. W tym wypadku sędzia odgrywa rolę odbiorcy tego wydarzenia. $Z$ kolei druga sztuka przedstawia proces jako całość, który jest grany przed opinią publiczną.

Po szóste, przedstawieniu teatralnemu i sądowemu przypisuje się charakter dramaturgiczny. Taka kwalifikacja w przypadku procesu sądowego jest konsekwencją rozstrzygania spraw o losach człowieka, w tym i - jak na przykład w sprawach karnych - najbardziej podstawowych. Mając na uwadze ten argument, a także interakcyjno-konfliktowy aspekt rozprawy, Grażyna Skąpska przedstawia dramaturgiczną wizję procesu sądowego ${ }^{17}$.

Wskazane racje, ilustrujące związek między teatrem a procesem sądowym, nie powinny jednak prowadzić do zacierania różnić między nimi. Służą one różnym celom, co najlepiej uwidacznia się we wpływie rozstrzygnięć sądowych na życie codzienne stron sporu ${ }^{18}$. Ponadto stopień „steatralizowania" ${ }^{19}$ procesu zależy od rodzaju sprawy: karna czy cywilna, a także wyboru modelu procedury sądowej. Mając jednak na uwadze wymienione wyżej racje, można dostrzec potencjał do budowania analogii między salą teatralną a sądową. $Z$ tego też powodu wizja rozprawy sądowej jako teatru jest obecna $\mathrm{w}$ dyskursie prawniczym, teorii społecznej, a także w przemyśle kinematograficznym ${ }^{20}$.

\section{Profesjonalizm w dramaturgicznej wizji roli}

Przedstawianie teatralności procesu sądowego skłania do pytania, kim staje się człowiek na sali sądowej. W aspekcie wizualizacyjnym do postawienia tej kwestii nakłania ubiór sędziego czy pełnomocnika procesowego w postaci togi ${ }^{21}$. A. Monks, na przykładzie stroju sędziego, opisuje przemianę, jaką przechodzi osoba wykonująca tę profesję. Przedstawiając ją, autor odwołuje się do wizji teatru kojarzonej z Konstantym Stanisławskim ${ }^{22}$. Zgodnie z nią aktor roztapia się $\mathrm{w}$ roli, a kostium sceniczny nie tylko jest ważnym elementem profesji zawodowej, lecz także podkreśla wpływ tożsamości zawodowej na to, kim staje się osoba. Zdaniem Richarda A. Wasserstroma zatopienie to obejmuje nie tylko

16 M.S. Ball, op. cit., s. 88. Zob. też K. Zeidler, Estetyka prawa, Gdańsk-Warszawa 2018, s. $149-150$.

17 G. Skąpska, Dramaturgia procesu sądowego, s. 58. Zob. też J. Chlebny, op. cit., s. 74; B. Tecław, op. cit., s. 252-253; D.J. Brion, op. cit., s. 342 n.

18 M.S. Ball, op. cit., s. 94-95.

19 J. Chlebny, op. cit., s. 82.

20 P. Robson, Theatre and the law in the twenty-first century, [w:] Cultural Legal Studies. Law's popular cultures and the metamorphosis of law, red. C. Sharp, M. Leiboff, Routledge 2016, s. 113 n.

21 A. Monks, op. cit., s. 488.

22 Ibidem, s. 487-488. 
aktywność zawodową, ale i pozostałe sfery życia codziennego, w których zaczyna się myśleć i postępować, zgodnie z wymogami profesji prawniczej. Jak odnotowuje amerykański badacz: ,z roli profesjonalisty trudno jest wyjść nawet w tych oczywistych sytuacjach, w których rola ta nie jest wymagana, ani odpowiednia. Profesjonalna rola staje się rolą dominującą, tak iż dla wielu osób pod wieloma ważnymi względami jest ona ich sposobem bycia"23.

Przedstawiony problem został trafnie ujęty w powieści Kazuo Ishiguro Okruchy dnia ${ }^{24}$. Akcja powieści osadzona jest $\mathrm{w}$ znacznej części $\mathrm{w}$ drugiej połowy lat dwudziestych ubiegłego wieku w Wielkiej Brytanii, w posiadłości Darlington Hall. Zaprezentowano w niej wiele historii, które można odczytać jako instruktaż profesjonalizmu, to jest standardów określających pożądany sposób postępowania. Głównym bohaterem książki jest kamerdyner Stevensa, który z gorliwością wykonuje wszelkie polecenia Lorda Darlingtona. Profesjonalizm, jaki uosabia postać majordomusa, polega na całkowitym oddaniu się odgrywanej roli ${ }^{25}$. Oddanie to charakteryzuje, po pierwsze, kierowanie się regułami i zasadami praktyki zawodowej w taki sposób, który wyłącza indywidualny osąd nad podejmowanymi czynnościami. W ujęciu tym nie ma innych czynników względem moralności instytucjonalnej, które mają wpływ na wykonywanie profesji ${ }^{26}$. I po drugie, wizja profesjonalizmu, jaką wyraża postać Stevensa, powoduje zawłaszczenie przez rolę zawodową pozostałych sfer życia codziennego. Proces ten może doprowadzić do sytuacji, w której instytucjonalna tożsamość staje się obrazem człowieka w różnych sferach aktywności. Racją przywoływaną na rzecz identyfikacji jednostki z rolą jest godność zawodowa, rozumiana przez Stevensa w następujący sposób:

jest nieodłącznie związana ze zdolnością kamerdynera do zachowywania niewzruszonej postawy zawodowej. Zły kamerdyner to taki, który z byle powodu zastępuje postawę zawodową postawą prywatną. [...] Wielki kamerdyner jest taki dlatego, że potrafi dopasować się i to całkowicie, do swojej roli ${ }^{27}$.

Aby uzasadnić działanie, które sprowadza się do bycia pasem transmisyjnym woli pracodawcy, można wskazać na dwa rodzaje racji. Pierwsza dotyczy woli pracodawcy. Zdaniem Stevensa lokaje powinni wybierać pracodawców, którzy

${ }^{23}$ R.A. Wasserstrom, Adwokaci jako profesjonaliści: kilka zagadnień moralnych, przeł. J. Malczewski, [w:] Moralność i profesjonalizm. Spór o pozycję etyk zawodowych, red. W. Galewicz, Kraków 2010, s. 281.

${ }^{24}$ K. Ishiguro, Okruchy dnia, przeł. J. Rybicki, Warszawa 2017.

${ }^{25} \mathrm{O}$ analogiach między pracą prawnika a kamerdynera w nawiązaniu do postaci Stevensa pisze D. Luban, Steven's Professionalism and Ours, „William \& Mary Law Review” 38, 1996, nr 1, s. 298; S. Daicoff, On Butlers, Architects, and Lawyers: the professionalism of 'The Remains of the Day' and 'the Fountainhead', ,Journal of Law, Business \& Ethics” 2011, nr 17, s. 23 n.

${ }^{26}$ R. Atkinson, How the Butler was made to do it: The Perverted Professionalism of the Remains of the Day, „The Yale Law Journal” 105, 1995, nr 1, s. 184-185.

27 K. Ishiguro, op. cit., s. 54. 
służą wzniosłym celom publicznym. Drugi argument odwołuje się do społecznego podziału pracy: zgodnie z nim odgrywanie roli kamerdynera powinno polegać na dostosowaniu się do reguł i zasad praktyki zawodowej.

Przedstawione ujęcie profesjonalizmu nie jest jedynym, jakie można odczytać z powieści Okruchy dnia. Inną wizję reprezentuje amerykański senator Lewis, który przybywa do posiadłości Lorda Darlington w celu podjęcia rozmów z przedstawicielami głównych sił politycznych w Europie na temat ładu społecznoustrojowego po I wojnie światowej. Profesjonalizm, który charakteryzuje postać senatora to uznanie, że cel uświęca środki. W ujęciu tym rekomendowaną postawę charakteryzuje cynizm, na co wskazuje zachowanie Lewisa. Senator, opisując pożądaną wizję profesjonalizmu, stwierdza: „Skończyły się czasy, gdy mogliście dawać upust tym waszym szlachetnym instynktom. [...]. Wam w Europie potrzeba teraz zawodowców [...]. A więc toast, panowie. Pozwólcie, że wniosę toast. Za profesjonalizm ${ }^{28}$ ".

Zdaniem Davida Lubana profesjonalizm Lewisa marginalizuje oceny moralne za cenę sprowadzenia spraw zawodowych do kwestii technicznych ${ }^{29}$. Tak rozumiany profesjonalizm jest poddawany krytyce przez gospodarza przyjęcia Lorda Darlingtona, który, w odpowiedzi na wspomniane wyżej słowa senatora, stwierdza: „wiem dość dobrze, co pan uznaje za »profesjonalizm«. Otóż polega on na dążeniu do własnych celów drogą oszust i manipulacji, cele te zaś określa chciwość i zaborczość, a nie pragnienie dobra i sprawiedliwości" ${ }^{30}$.

Wymienione wizje profesjonalizmu, które charakteryzują postacie kamerdynera i senatora, można odnieść do dramaturgicznej wizji roli w metaforze teatralnej E. Goffmana ${ }^{31}$. Ujęcie to zakłada, że odgrywanie roli jest występem, który może prowadzić do dwóch obrazów etosu zawodowego. Charakteryzuje je odpowiednio postawa identyfikacji z rolą i instrumentalny dystans do profesji ${ }^{32}$. Pierwszą $\mathrm{z}$ wymienionych postaw badacz życia codziennego charakteryzuje w taki sposób: „Oddać się roli to zniknąć całkowicie w wykreowanej (virtual) osobowości dostępnej w danej sytuacji, być postrzeganym całkowicie w kategoriach określonego wizerunku i akceptować go. Oddać się roli to oddać się w jej władanie" 33 . Z kolei drugą z postaw Goffman przedstawia w następujący sposób: „Należy zdawać sobie sprawę z tego, że cynika, mimo profesjonalnej obojętności, może prywatnie radować uprawiana maskarada, która pozwala mu doświadczać pewnego rodza-

${ }^{28}$ K. Ishiguro, op. cit., s. 131.

29 D. Luban, op. cit., s. 305-306.

30 K. Ishiguro, op. cit., s. 132.

31 Erving Goffman, charakteryzując książkę Człowiek $w$ teatrze życia codziennego, pisze: „Perspektywa przyjęta w tej pracy to perspektywa przedstawienia teatralnego: reguły, które będę opisywać, są regułami dramaturgicznymi”, idem, Człowiek w teatrze..., s. 27.

32 Ibidem, s. 47-49. Postawy te przedstawiam w pracy P. Kaczmarek, Dystans do roli w zawodzie prawnika, Warszawa 2019, s. 136-143.

33 E. Goffman, Dystans do roli, [w:] idem, Spotkania. Dwa studia z socjologii interakcji, przeł. P. Tomanek, Kraków 2010, s. 86. 
ju złośliwej satysfakcji, iż potrafi bawić się do woli czymś, co jego publiczność musi traktować zupełnie serio" 34 . Można zatem powiedzieć, że w wizji tej profesjonalizm polega na kamuflażu, który ma prowadzić do realizacji celów, często niewyrażanych wprost, a więc nieraz niedostrzegalnych przez publiczność, a także ekspertów.

Profesjonalizm Stevensa jest tym, za którym w dyskursie prawniczym opowiada się W. Bradley Wendel ${ }^{35}$. Autor, rekomendując tego rodzaju profesjonalizm, wskazuje na dwie racje. Pierwsza z nich odsyła do założeń systemu kontradyktoryjnego, zgodnie z którym podział na obrońcę i oskarżyciela służy ochronie praw jednostki, a także zapewnia sprawiedliwy proces. W argumentacji tej celem profesji prawniczej jest dostosowanie się do moralności instytucjonalnej. Jej odrębność od racji, zwłaszcza indywidualnych, sprzyja dobremu wykonywaniu pełnionej funkcji. Z kolei druga linia argumentacyjna odwołuje się do uwzględniania racji klienta. Zasada lojalności ma szczególne zastosowanie w przypadku pełnomocnika procesowego. Podnosząc ten aspekt podkreśla się, że jest on przyjacielem do specjalnych celów ${ }^{36}$. Stephen Pepper zauważa dodatkowo, że atutem tak rozumianego profesjonalizmu jest odciążenie prawnika od dylematów moralnych. Działanie, jakie wykonuje pełnomocnik procesowy, jest bowiem racjonalizowane jako instytucjonalne, a więc w pewien sposób niezależne od osoby ${ }^{37}$.

Przedstawiona wizja profesjonalizmu może jednak okazać się kłopotliwa zarówno z perspektywy zawodowej, jak i osobistej. Możemy się o tym przekonać, śledząc dialogi między pracodawcą (Lordem Darlington) a kamerdynerem (Stevens) czy też między wykonawcami roli, to jest Stevensem a Panną Kenton, również pracującą w posiadłości Darlington Hall ${ }^{38}$. Koszt niebezpieczeństwa, w obu wymienionych aspektach, trafnie ilustruje jedna z końcowych scen, w której Stevens wypowiada następujące słowa:

Lord Darlington nie był złym człowiekiem. Na pewno nie. A pod koniec życia potrafił przynajmniej powiedzieć, że popełniał błędy. Jego lordowska mość był człowiekiem odważnym. Obrał w życiu jakąś drogę, okazało się, że niesłuszną, ale przynajmniej coś wybrał. A ja? Ja nie mogę powiedzieć o sobie nawet tego. Bo widzi pan, ja wierzyłem, wierzyłem w mądrość jego lordowskiej mości. Przez wszystkie te lata, kiedy mu służyłem, wierzyłem, że robię coś, co warto. Tymczasem nie mogę nawet powiedzieć, że popełniałem własne błędy. Doprawdy, nasuwa się pytanie, i jakaż w tym godność? ${ }^{39}$.

34 E. Goffman, Człowiek w teatrze..., s. 48.

35 W.B. Wendel, Lawyers and Butlers: The Remains of Amoral Ethics, „Georgetown Journal of Legal Ethics" 1995, nr 9, s. 162-163.

36 R. Atkinson, A Dissenter's Commentary on the Professionalism Crusade, „Texas Law Review" 1996, nr 74, s. 304-305.

37 S.L. Pepper, The Lawyer's Amoral Ethical Role: a defense, a problem, and some possibilities, „American Bar Foundation Research Journal” 1986, nr 4, s. 635.

38 Dialogi te analizuje R. Atkinson, How the Butler was mad..., s. $196 \mathrm{n}$.

39 K. Ishiguro, op. cit., s. 300. 
Niebezpieczeństwo zatracenia się w tożsamości zawodowej staje się jeszcze bardziej realne jeśli przyjmiemy, zgodnie z profesjonalizmem Stevensa, po pierwsze - separację moralności społeczno-indywidualnej od moralności instytucjonalnej, i po drugie — odrębność praktyki zawodowej od pozostałych sfer życia społecznego ${ }^{40}$.

Przedstawiony zarys profesji jako gry teatralnej podaje w wątpliwość J.S. Peters ${ }^{41}$. Głównym zarzut, jaki formułuje autorka, to ujęcie roli jako przedstawienia teatralnego marginalizującego sprawczość podmiotową jurysty oraz pozycję publiczności ${ }^{42}$. Akceptacja tego zarzutu nie musi jednak oznaczać rezygnacji z perspektywy teatralnej. Możemy się o tym przekonać, śledząc rozważania Maretty Leiboff $^{43}$. Autorka przedstawia projekt jurysprudencji teatralnej, który zakłada, po pierwsze - umiejętność zachowania przez prawników samoświadomości, po drugie - aktywizm prawniczy, zgodnie z przekonaniem, że jakość prawa zależy również od interpretatora, od tego kim jest w życiu codziennym, i po trzecie w przypadku pełnomocnika procesowego wygłoszenie publicznie racji klienta $i$ ich obrona $^{44}$. Eksponując te właściwości Maretta Leiboff zwraca uwagę na propozycję teatru, jaką przedstawia ją Hans-Thies Lehmann, a także Jerzy Grotowski ${ }^{45}$.

\section{W stronę liminalnej teatralności procesu sądowego}

Przyczyn zainteresowania propozycją J. Grotowskiego można upatrywać w cechach teatralności, za jakimi opowiada się ceniony teatrolog ${ }^{46}$. Pierwsza z nich dotyczy przestrzeni teatralnej. W tym zakresie autor opowiada się za wizją teatru ubogiego ${ }^{47}$. Zgodnie $\mathrm{z}$ nią przedstawienie teatralne powinno charakteryzować odejście od monumentalnej rozbudowy architektury wnętrza na rzecz koncentrowania się przy jej konstruowaniu na relacji aktor-widz ${ }^{48}$. Zdaniem J. Grotowskiego podział sali teatralnej na strefy prowadzi do ograniczenia dostępności

40 J.S. Peters, op. cit., s. 182-183.

41 Ibidem, s. 179 n.

42 Ibidem, s. $191 \mathrm{n}$.

43 M. Leiboff, Towards a Theatrical Jurisprudence, Abingdon 2019.

44 Ibidem, s. 9 i 58-59.

45 Ibidem, s. 100. Zob. też D. Sheikh, Book Review: Marett Leiboff, Towards a Theatrical Jurisprudence (Abingdon: Routledge, 2019), „Law \& Literature” 33, 2021, nr 1, s. 166-168; P. Goodrich, Inutilious Propaedeutics: Performances in Theatre and Law, „Social \& Legal Studies” 29, 2020, nr 4, s. $596 \mathrm{n}$.

46 Właściwości te można odnieść do teatru postdramatycznego, zob. M. De Marinis, Performans i teatr. Od aktora do performera i z powrotem?, „Performer” 2012, nr 5, zwl. s. 33-34.

47 J. Grotowski, Ku teatrowi ubogiemu, [w:] idem, Teksty z lat 1965-1969. Wybór, Wrocław 1999, s. 12.

48 J. Grotowski, Teatr Laboratorium ,13 Rzędów” Jerzy Grotowski o sztuce aktora, [w:] idem, Teksty z lat..., s. 34 . 
do niej, a w konsekwencji marginalizacji aktywnego udziału w przedstawieniu, zwłaszcza po stronie publiczności.

Druga właściwość dotyczy kondycji moralnej i fizycznej aktora. Przedstawiając oba te aspekty, J. Grotowski wskazuje na spektakl teatralny jako akt transgresji ${ }^{49}$. W wymiarze tożsamościowym autor zwraca uwagę na konieczność wypracowywania umiejętności zachowania podmiotowości, odrębności aktora od praktyki zawodowej. Z kolei aspekt cielesności jest podnoszony w celu podkreślenia tego wymiaru jako jednej z ważnych form ekspresji aktora ${ }^{50}$.

Trzecia cecha odnosi się do wykonywania roli. W tym zakresie J. Grotowski proponuje wizję teatru jako rytuału ${ }^{51}$. Przedstawiając ją, autor wskazuje na kilka właściwości. Jedną z nich jest, podkreślana już wcześniej, podmiotowość. Zachowanie jej w ramach zastanego stanu faktycznego zakłada uczestniczenie człowieka w przedstawieniu, którego nie można sprowadzić do aspektu technicznego. Wyrazem tego jest sytuacja wyboru, branie przez aktora pod uwagę różnych wariantów działania ${ }^{52}$. Dla rytualnej wizji teatru kluczowa staje się relacja między aktorem a tekstem, określającym obraz roli. Tak ją charakteryzuje J. Grotowski: „Nie da się powiedzieć, że rola jest pretekstem dla aktora, ani że aktor jest pretekstem dla roli; to jest raczej wyzwanie [...]"53. Można zatem powiedzieć, że tekst dla aktora jest tym, czym nuty dla muzyka: korzystanie z nich wymaga aktywności interpretatora.

Wymienione właściwości łączy metafora wieży Babel ${ }^{54}$. J. Grotowski posługuje się nią na oznaczenie procesu odejścia od totalizacji jednego punktu widzenia, które zamyka człowieka w praktyce instytucjonalnej na rzecz łączenia różnych systemów wartości, konwencji działania. Taka wizja praktyki teatralnej odwołuje się do idei liminalności, na co zwraca uwagę Victor Turner. Zdaniem tego antropologa, umiejętność wykonywania wielu ról w życiu codziennym, bez zatracenia się $\mathrm{w}$ jednej praktyce, nawet tej dominującej, obecna jest w projekcie J. Grotowskiego ${ }^{55}$. Dla porządku odnotujmy, że V. Turner, dokonując tego przyporządkowania, posługuje się pojęciem liminalności na oznaczenie sytuacji, w której ludzie są ,jednocześnie członkami dwóch lub więcej grup społecznych,

49 J. Grotowski, Ku teatrowi..., s. 15.

50 J. Grotowski, Aktor ogołocony, [w:] Teksty z lat..., s. 22.

51 J. Grotowski, Teatr a rytuat, [w:] Teksty z lat..., s. 61 n.

52 J. Grotowski, D. Bablet, Techniki aktorskie. Rozmowa z Jerzym Grotowskim, [w:] Teksty z lat..., s. 55 .

53 Ibidem, s. 56.

54 J. Grotowski, Teatr a rytuat, s. 71.

55 V. Turner, Od rytualu do teatru. Powaga zabawy, przeł. M. i J. Dziekanowie, Warszawa 2005, s. 169 n.; idem, Gry społeczne, pola i metafory. Symboliczne działanie w spoleczeństwie, przeł. W. Usakiewicz, Kraków 2005, s. 200; idem, Proces rytualny. Struktura i antystruktura, przeł. E. Dżurak, Warszawa 2010, s. 115 n. 
których społeczne zdefiniowanie i normy kulturowe są różne, a często nawet sprzeczne" $" 56$.

Podążając ścieżką interpretacyjną, zaproponowaną przez V. Turnera, można odnieść ideę liminalności do wskazanych wyżej trzech cech teatralności. W tym celu skorzystam z ustaleń Jonasa Söderlunda i Elisabeth Borg, którzy przedstawiają liminalność jako: a) proces, b) pozycję i c) przestrzeń ${ }^{57}$.

Pierwsze z wymienionych ujęć liminalności dotyczy modelowania tożsamości na różnych identyfikacjach, które można przyporządkować do praktyk, w których uczestniczymy. Mając wpływ na to, kim jesteśmy, żadna z tych identyfikacji nie marginalizuje podmiotowości jednostki. W tym aspekcie liminalność podkreśla umiejętność dostosowania się do nowego kontekstu, na przykład z powodu zmiany organizacji społecznej. Wskazana metadyspozycja o charakterze dyrektywalnym jest znakiem rozpoznawczym liminalności jako procesu. Ujęcie to, jak się wydaje, można odnieść do ustaleń J. Grotowskiego w zakresie tożsamości aktora. Przedstawiając ją, autor podkreśla wagę zachowania odrębności jednostki od praktyk społecznych, przy jednoczesnym uczestniczeniu w nich. Drugie z wyróżnionych ujęć przedstawia liminalność jako pozycję. Dotyczy ono zajmowanego stanowiska, które charakteryzuje złożoność identyfikacji i często również odmienność zadań. Taki opis liminalności można łączyć z rolą jako rytuałem w ujęciu Grotowskiego. Trzecie ujęcie liminalności, jako przestrzeni, koncentruje się na architekturze miejsca i jej wpływie na interakcje między uczestnikami praktyki społecznej. Ten aspekt liminalności można z kolei powiązać z ustaleniami interesującego nas teatrologa w zakresie przestrzeni teatralnej.

Wymienione ujęcia liminalności łączy osłabienie opozycji wewnętrznyzewnętrzny punkt widzenia $\mathrm{w}$ przedstawianiu badanej praktyki, a także wizja kształtowania tożsamości wykonawcy roli. Idea liminalności podkreśla bowiem odejście od perspektywy, która dzieli osoby na uczestników i obserwatorów. Z kolei w wymiarze tożsamościowym liminalność wzmacnia poczucie siebie, stałości, poprzez kształtowanie osobowości na dwóch filarach: narracji i fragmentaryzacji. O ile pierwszy z nich eksponuje zdolność zachowania podmiotowości, o tyle fragmentaryzacja podkreśla umiejętność dostosowania się do praktyk życia codziennego, ról, jakie w nich odgrywamy. Idea liminalności zakłada zatem odejście od pozycjonowania człowieka na jednej identyfikacji. W zamian proponuje wyposażenie jednostki w metadyspozycję do uwzględniania w sytuacji działania kontekstu sytuacyjnego i tę umiejętność można traktować jako niezbędną dla właściwego wykonywania zawodu. Atutem tego rozwiązania jest odejście od wizji,

56 V. Turner, Gry społeczne..., s. 196-197.

57 J. Söderlund, E. Berg, Liminality in management and organization studies: process, position and place, „International Journal of Management Reviews” 2018, nr 20, s. 884 n. Ujęcia te szerzej przedstawiłem w artykule P. Kaczmarek, Wykonywanie roli zawodowej: prawnik liminalny, „Ruch Prawniczy, Ekonomiczny i Socjologiczny” 2020, z. 3, s. 22-23. 
w której profesjonalizm rozumiany jest jako dostosowanie się do jednowymiarowego zobowiązania, na przykład lojalności wobec klienta.

\section{Uwagi końcowe}

Przedstawienie procesu sądowego jako teatru pozwoliło zarysować dwie wizje profesjonalizmu. Próbując je przybliżyć, odwołałem się do postaci kamerdynera Stevensa i senatora Lewisa z powieści Okruchy dnia. Uosabiają one odmienne ujęcia profesjonalizmu. Łączy je jednak:

a) teza o wewnętrznym i zewnętrznym punkcie widzenia, która zakłada podział na uczestników praktyki i obserwatorów, niemających wglądu w warsztat zawodowca,

b) teza o separacji moralności zawodowej od moralności społecznej i indywidualnej.

Oba te twierdzenia można podać w wątpliwość w świetle cech teatralności, jakie proponuje J. Grotowski. Propozycja ta, jak starałem się wykazać, oparta jest na idei liminalności. Ujęcie w jej świetle procesu sądowego pozwala zaproponować:

a) sprawczą podmiotowość sędziego, prawnika, a także pozostałych uczestników postępowania, co przekłada się na prawo dostępności do wymiaru sprawiedliwości,

b) metadyspozycję do wykonywania wielu ról społecznych, co może stanowić mechanizm obronny przed syndromem oddania się roli.

Liminalne ujęcie teatralności procesu sądowego jest warte dalszych badań również dlatego, że pozwala — pozostając w perspektywie teatralnej — podać w wątpliwość wizję dramaturgiczną. Fundowane na niej dwie wizje profesjonalizmu, które uosabiają postaci Stevensa i Lewisa, budzą zastrzeżenia. Pod osłoną maski, jaką może pełnić argument z roli, mogą ukrywać się działania również kosztowne, tak z punktu widzenia społeczno-zawodowego, jak i osobistego. Cennej w tym zakresie lekcji udziela nam historia Stevensa.

\section{Bibliografia}

Atkinson R., A Dissenter's Commentary on the Professionalism Crusade, „Texas Law Review” 1996, nr 74.

Atkinson R., How the Butler was made to do it: The Perverted Professionalism of the Remains of the Day, ,The Yale Law Journal” 105, 1995, nr 1.

Ball M.S., The Play's the Thing: An Unscientific Reflection on Courts Under the Rubric of Theater, „Stanford Law Review” 28, 1975, nr 1.

Boss A.G., (Un)Related Purposes: Theatre and Law, „Canadian Theatre Review” 2010, nr 142.

Brion D.J., The Criminal Trial as Theater: The Semiotic Power of the Image, [w:] Law, Culture and Visual Studies, red. A. Wagner, R.K. Sherwin, Dordrecht 2014. 
Chlebny J., Dramaturgia sali sądowej. Próba zastosowania kategorii Ervinga Goffmana, [w:] Etyka zawodów prawniczych w praktyce. Wzajemne relacje i oczekiwania, red. G. Borkowski, Lublin 2012.

Daicoff S., On Butlers, Architects, and Lawyers: the professionalism of 'the Remains of the Day' and 'the Fountainhead', „Journal of Law, Business \& Ethics” 2011, nr 17.

De Marinis M., Performans i teatr. Od aktora do performera i z powrotem?, „Performer” 2012, nr 5.

Gemli C., Staging the Nation: Theatricality in the Law, „Elements” 2005, nr 1.

Gilbert R., Editorial, „Canadian Theatre Review”2010, nr 142.

Goffman E., Człowiek w teatrze życia codziennego, przeł. H. Datner-Śpiewak, P. Śpiewak, Warszawa 2008.

Goffman E., Dystans do roli, [w:] Spotkania. Dwa studia z socjologii interakcji, przeł. P. Tomanek, Kraków 2010.

Goodrich P., Europe in America: Grammatology, Legal Studies, and the Politics of Transmission, „Columbia Law Review” 101, 2001, nr 8.

Goodrich P., Inutilious Propaedeutics: Performances in Theatre and Law, „Social \& Legal Studies” 29, $2020, \mathrm{nr} 4$.

Grotowski J., Aktor ogolocony, [w:] Teksty z lat 1965-1969. Wybór, Wrocław 1999.

Grotowski J., Ku teatrowi ubogiemu, [w:] Teksty z lat 1965-1969. Wybór, Wrocław 1999.

Grotowski J., Teatr a rytuat, [w:] Teksty z lat 1965-1969. Wybór, Wrocław 1999.

Grotowski J., Teatr Laboratorium „13 Rzędów” Jerzy Grotowski o sztuce aktora, [w:] Teksty z lat 1965-1969. Wybór, Wrocław 1999.

Grotowski J., Bablet D., Techniki aktorskie. Rozmowa z Jerzym Grotowskim, [w:] Teksty z lat 19651969. Wybór, Wrocław 1999.

Ishiguro K., Okruchy dnia, przeł. J. Rybicki, Warszawa 2017.

Kaczmarek P., Dystans do roli w zawodzie prawnika, Warszawa 2019.

Kaczmarek P., Wykonywanie roli zawodowej: prawnik liminalny, „Ruch Prawniczy, Ekonomiczny i Socjologiczny" 2020, z. 3.

Lehmann H.T., Teatr postdramatyczny, przeł. D. Sajewska, M. Sugiera, Kraków 2004.

Leiboff M., Towards a Theatrical Jurisprudence, Abingdon 2019.

Luban D., Steven's Professionalism and Ours, „William \& Mary Law Review” 38, 1996, nr 1.

Monks A., Dressing the law, „International Journal of Law in Context” 14, 2018 , nr 4.

Nikova J.N., The concept of 'theatricality' in legal performance with respect to musicians and the way they engage with the law, http://lawreview.elsa-spain.org/wp-content/uploads/2017/06/ Art5.pdf.

Pepper S.L., The Lawyer's Amoral Ethical Role: a defense, a problem, and some possibilities, „American Bar Foundation Research Journal” 1986, nr 4.

Peters J.S., Legal Performance Good and Bad, „Law, Culture and the Humanities” 2008, nr 4.

Robson P., Theatre and the law in the twenty-first century, [w:] Cultural Legal Studies. Law's popular cultures and the metamorphosis of law, red. C. Sharp, M. Leiboff, Routledge 2016.

Rogers N., The Play of law: Comparing performances in law and theatre, „QUT Law Review” 8, 2008, $\mathrm{nr} 2$.

Sheikh D., Book Review: Marett Leiboff, Towards a Theatrical Jurisprudence (Abingdon: Routledge, 2019), „Law \& Literature” 33, 2021, nr 1.

Skąpska G., Dramaturgia procesu sądowego, [w:] G. Skąpska, J. Czapska, M. Kozłowska, Społeczne role prawników (sędziów, prokuratorów, adwokatów), Wrocław 1980.

Söderlund J., Berg E., Liminality in management and organization studies: process, position and place, „International Journal of Management Reviews” 2018, nr 20.

Szerer M., Kultura i prawo, Warszawa 1981.

Świerczyńska-Głownia W., Komunikowanie z perspektywy sali sądowej, Kraków 2019. 
Tecław B., Rozprawa sądowa jako spektakl teatralny, [w:] Język prawny i prawniczy. I Kongres ogólnopolski, red. D. Kondratczyk-Przybylska, A. Niewiadomski, E. Walewska, Warszawa 2017.

Tokarczyk R., Proksemika ogólna jako podstawa proksemiki sądowej i proksemiki prawniczej, „Annales Universitatis Mariae Curie-Skłodowska, Secio G” 56-57, 2009-2010.

Turner V., Gry spoleczne, pola i metafory. Symboliczne dziatanie w społeczeństwie, przeł. W. Usakiewicz, Kraków 2005.

Turner V., Od rytuału do teatru. Powaga zabawy, przeł. M. i J. Dziekanowie, Warszawa 2005.

Turner V., Proces rytualny. Struktura i antystruktura, przeł. E. Dżurak, Warszawa 2010.

Vismann C., "Rejouer les crimes” Theater vs. Video, „Cardozo Studies in Law and Literature” 13, 2001, nr 1 .

Wasserstrom R.A., Adwokaci jako profesjonaliści: kilka zagadnień moralnych, przeł. J. Malczewski, [w:] Moralność i profesjonalizm. Spór o pozycję etyk zawodowych, red. W. Galewicz, Kraków 2010.

Wendel W.B., Lawyers and Butlers: The Remains of Amoral Ethics, „Georgetown Journal of Legal Ethics" 1995, nr 9.

Zeidler K., Estetyka prawa, Gdańsk-Warszawa 2018.

Znaniecki F., Relacje społeczne i role społeczne. Niedokończona socjologia systematyczna, przeł. E. Hałas, Warszawa 2001. 